\title{
Green synthesis of copper nanoparticles using Eclipta prostrata leaves extract and their antioxidant and cytotoxic activities
}

\author{
ILL-MIN CHUNG ${ }^{1}$, ABDUL ABDUL RAHUMAN $^{2}$, SAMPATH MARIMUTHU $^{2}$, ARIVARASAN VISHNU KIRTHI $^{2}$, \\ KARUNANITHI ANBARASAN ${ }^{2}$, PARTHASARATHY PADMINI ${ }^{3}$ and GOVINDASAMY RAJAKUMAR ${ }^{1}$ \\ ${ }^{1}$ Department of Applied Bioscience, College of Life and Environmental Science, Konkuk University, Seoul 143701 , \\ Republic of Korea; ${ }^{2}$ Unit of Nanotechnology and Bioactive Natural Products, \\ Post Graduate and Research Department of Zoology, C. Abdul Hakeem College, Vellore, Tamil Nadu 632 509, \\ India; ${ }^{3}$ Department of Biochemistry, University of Otago, North Dunedin, Dunedin, Otago 9016, New Zealand
}

Received August 31, 2015; Accepted November 18, 2016

DOI: $10.3892 /$ etm.2017.4466

\begin{abstract}
The present study outlines the development of a method to synthesize copper nanoparticles (CuNPs) by mixing copper acetate solution with leaf extract of Eclipta prostrata without using any surfactant or external energy. E. prostrata leaf extract function as an excellent reducing agent of copper ions, and the biosynthesized CuNPs are safer for the environment. The powder X-ray diffraction (XRD) pattern provided evidence for the formation of face-centered cubic structure ranging from 23 to $57 \mathrm{~nm}$, with an average size of $31 \pm 1.2 \mathrm{~nm}$. Fourier transform infrared spectroscopy (FTIR) was used to identify the biomolecules and capping reagents in the E. prostrata leaf extract that may be responsible for the reduction of copper ions and the stability of the bioreduced nanoparticles. The biosynthesized CuNPs displayed considerable antioxidant capacity. Similarly, in vitro anticancer studies demonstrated the cytotoxicity value of synthesized CuNPs against tested HepG2 cells. The findings of the present study suggested that biosynthesized CuNPs that utilize extracts of E. prostrata may be used for therapeutic application, and thus are a promising nanomaterial.
\end{abstract}

\section{Introduction}

Copper nanoparticles (CuNPs) have been used various fields, including agricultural, industrial engineering and technological fields. In recent years, research in the field of agriculture has focused on the impact of certain minor elements on the economy of plants. Bionanotechnology utilizes biological

Correspondence to: Dr Govindasamy Rajakumar, Department of Applied Bioscience, College of Life and Environmental Science, Konkuk University, 120 Neungdong-ro, Gwangjin-gu, Seoul 143 701, Republic of Korea

E-mail: microlabsraj@gmail.com

Key words: biosynthesis, nanoparticles, Fourier transform infrared spectroscopy, X-ray techniques, electron microscopy principles and physical and chemical approaches to yield nanosized particles with specific functions. Although the use of nanoscience in agriculture has been predominantly theoretical up to now, effective antibacterial activities exhibited by CuNPs in agricultural research have increased development in the field of nanotechnology, leading to the establishment of intensively clean, cost-effective and efficient biosynthesis techniques of CuNPs (1).

CuNP synthesis has attracted particular interest, compared with other NPs, as their useful properties are achievable at costs lower than silver and gold (2). Research into CuNPs has made significant progress in the areas of nanotechnology and nanomedicine within the last decade due to their excellent catalytic, optical, electrical and antifungal/antibacterial applications $(3,4)$. CuNPs have been prepared using thermal reduction (5) and a polyol method developed by Park et al (6). In recent years, plant-mediated biological synthesis of nanoparticles has gained interest due to its simplicity and eco-friendliness.

Although the biosynthesis of CuNPs by plants such as Euphorbia nivulia (7), Magnolia Kobus (8), Nerium oleander (9) has previously been reported, the potential of plants as biological materials for the synthesis of nanoparticles is yet to be fully explored. The bioactivities of Eclipta prostrata, which is a widely used traditional medicine and functional food, have been extensively explored (10). Previous phytochemical studies on E. prostrata revealed the presence of thiophene-derivatives, steroids, triterpenes (11), flavonoids, polyacetylenes, polypeptides and coumestons (12). Various herbal preparations that include E. prostrata are available for the treatment of diverse symptoms, including hyperlipidemia, atherosclerosis and skin diseases (13). The present study aimed to develop a method of rapidly synthesizing CuNPs using aqueous leaf extract of E. prostrate, and their antioxidant activities were subsequently evaluated.

\section{Materials and methods}

Preparation of E. prostrata leaf broth. Analytical grade copper acetate $\mathrm{Cu}(\mathrm{OAc})_{2}$ was purchased from Merck Millipore (Darmstadt, Germany). All other reagents used in the present 
study were of analytical grade. Aqueous extract of E. prostrata was prepared using freshly amassed leaves $(10 \mathrm{~g})$ which were collected from Melvisharam Tamil Nadu, India $\left(12^{\circ} 56^{\prime} 23^{\prime \prime} \mathrm{N}\right.$, $\left.79^{\circ} 14^{\prime} 23^{\prime \prime} \mathrm{E}\right)$. The surfaces of the leaves were cleaned with running tap water followed by distilled water and the leaves were subsequently boiled in $100 \mathrm{ml}$ double distilled water at $80^{\circ} \mathrm{C}$ for $30 \mathrm{~min}$. The extract was filtered through Whatman No.1 filter paper and used for subsequently analyses.

Biosynthesis of CuNPs. To synthesize the CuNPs, an Erlenmeyer flask containing $100 \mathrm{ml}$ copper acetate $\mathrm{Cu}(\mathrm{OAc})_{2}$ (3 $\mathrm{mM}$ ) was stirred for $2 \mathrm{~h}$. Following this, $20 \mathrm{ml}$ of the aqueous extract of E. prostrata was added with $80 \mathrm{ml}$ of $3 \mathrm{mM}$ $\mathrm{Cu}(\mathrm{OAc})_{2}$ at room temperature and was subsequently stirred for $24 \mathrm{~h}(14)$.

Characterization of $C u N P$ s. The following procedures and equipment were used to characterize the nanoparticles using standard protocols: i) Ultraviolet (UV-)visible spectra using a Lambda 2 spectrophotometer (PerkinElmer, Inc., Waltham, MA, USA) in the $300-800 \mathrm{~nm}$ wavelength range; ii) X-ray diffraction (XRD) analysis of $\mathrm{Cu} \mathrm{K \alpha} \alpha_{1}$ (wavelength, $1.54060 \mathrm{~A}^{\circ}$ ) using an automatic X-ray diffractometer with a Philips PW 1830 X-ray generator (Phillips Healthcare, DA Best, The Netherlands); iii) fourier transform infrared spectroscopy (FTIR) analysis using a Spectrum One FTIR spectrophotometer (PerkinElmer, Inc.); iv) scanning electron microscope (SEM) analysis using a JFC-1600 instrument (JEOL, Ltd., Tokyo, Japan) equipped with an energy-dispersive X-ray (EDX) attachment; and v) for high-resolution transmission electron microscopy (HRTEM; Carl Zeiss Microimaging, $\mathrm{GmbH}$, Mikroskopie, Germany) with selected area diffraction (SAED; Carl Zeiss Microimaging $\mathrm{GmbH}$ ) was used.

Evaluation of total antioxidant activity. Total antioxidant activities of the samples of synthesized CuNPs and aqueous leaf extract were analyzed according to the method outlined by Prieto et al (15). Briefly, $100 \mathrm{mg}$ of the synthesized CuNPs were mixed with $0.05 \%$ DMSO in the reaction vial and a $0.1-\mathrm{ml}$ aliquot of the sample was subsequently mixed with $1 \mathrm{ml}$ of the reagent solution $(0.6 \mathrm{M}$ sulphuric acid, $28 \mathrm{mM}$ sodium phosphate and $4 \mathrm{mM}$ ammonium molybdate). The tubes were capped and incubated at $95^{\circ} \mathrm{C}$ for $90 \mathrm{~min}$. After the samples were cooled to $25^{\circ} \mathrm{C}$, absorbance was measured at $695 \mathrm{~nm}$ against a blank, which contained $1 \mathrm{ml}$ of the reagent solution without the sample. Total antioxidant activity was expressed as the absorbance of the sample. A high absorbance value indicates increased antioxidant activity. Ascorbic acid was also assayed for comparison, using the same protocol.

Determination of total phenolic content (TPC). TPC was determined by the Folin-Ciocalteau method with some modifications (16). Briefly, $1 \mathrm{~g}$ per $10 \mathrm{ml}$ of sample was filtered with Whatman no.1 paper, and $0.5 \mathrm{ml}$ of the sample was subsequently incubated with $2.5 \mathrm{ml}$ of Folin-Ciocalteau reagents $(0.2 \mathrm{~N})$ for $5 \mathrm{~min}$. Following this, $2 \mathrm{ml}$ of $\mathrm{Na}_{2} \mathrm{CO}_{3}$ $(75 \mathrm{~g} / \mathrm{l})$ was added to the total volume, which was made up to $25 \mathrm{ml}$ using distilled water. This solution was then incubated at room temperature for $2 \mathrm{~h}$. Following incubation, absorbance was measured at $760 \mathrm{~nm}$ using a $1-\mathrm{cm}$ cuvette in a UV-Vis lambda spectrophotometer (PerkinElmer, Inc.). Tannic acid (0-800 mg/l) was used to produce a standard calibration curve. The TPC was expressed in mg of tannic acid equivalents (TAE)/g of the extract.

1,1-diphenyl-2-picryl-hydrazyl (DPPH) free radical scavenging assay. The DPPH free radical scavenging assay was performed according to the method outlined by Liyana-Pathiranan and Shahidi (17). Briefly, $1 \mathrm{ml}$ of each of the different concentrations (100-500 mg in methanol) of synthesized CuNPs and aqueous leaf extract was added to $1 \mathrm{ml}$ of $0.135 \mathrm{mM}$ DPPH in methanol solution. The reaction mixture was incubated in the dark room for $30 \mathrm{~min}$ of room temperature. The absorbance of the mixture was subsequently measured at $517 \mathrm{~nm}$ using a spectrophotometer.

Cytotoxicity study of HepG2 cell line. Viability of HepG2, A549, BEAS-2B, and primary rat cells (hepatocytes and astrocytes) was assessed by the MTT assay, as described by Mossman (18) with some modifications (19). Briefly, $1 \times 10^{4}$ cells/well were seeded in a 96-well plate and exposed to CuNPs and aqueous leaf extract of $E$. prostrata at concentrations of $1,10,100,250$ and $500 \mu \mathrm{g} / \mathrm{ml}$ for $24 \mathrm{~h}$. Following exposure, Dulbecco's modified Eagle's medium (Sigma-Aldrich, Merck Millipore, Darmstadt, Germany), the culture medium was removed from each well to avoid interference of the CuNPs with the aqueous leaf extract of E. prostrata. The medium was replaced with fresh medium containing MTT solution $(0.5 \mathrm{mg} / \mathrm{ml})$ in an amount equal to $10 \%$ of culture volume and the cells were incubated for $3 \mathrm{~h}$ at $37^{\circ} \mathrm{C}$ until a purple-colored formazan product developed. The resulting formazan product was dissolved in acidified isopropanol. Subsequently, the 96-well plate was centrifuged at $2,300 \times \mathrm{g}$ at $4^{\circ} \mathrm{C}$ for $5 \mathrm{~min}$ to settle the remaining CuNPs and aqueous leaf extract of E. prostrata and a $100-\mu 1$ supernatant was transferred to the fresh wells of a 96-well plate, and absorbance was measured at $570 \mathrm{~nm}$ using a microplate reader (FLUOstar Omega; BMG Labtech, Cary, NC, USA).

Statistical analysis. All experiments were performed in triplicate. For the experiments of antioxidant activity, arithmetic mean values were considered for data analysis. For comparison of the data obtained by these nanoparticles, an unpaired Student's $t$-test was performed. All the statistical analysis was performed using SPSS version 18 (SPSS, Inc., Chicago, IL, USA).

\section{Results}

CuNP synthesis. At a wavelength of $565 \mathrm{~nm}$, the optimum parameter required for CuNPs synthesis is $50^{\circ} \mathrm{C}, 3 \mathrm{mM}$ $\mathrm{Cu}(\mathrm{OAc})_{2}(\mathrm{pH} \mathrm{6})$ and a $30-\mathrm{min}$ incubation period. The formation of CuNPs was preliminarily confirmed by UV-Vis spectral analysis of colored solutions, which exhibited SPR bands within $1 \mathrm{~h}$; the bands were red-like in color, indicating metallic copper. The characteristic absorption peak at $565 \mathrm{~nm}$ is due to the surface plasmon band of $\mathrm{Cu}$ colloids formation of non-oxidized CuNPs (Fig. 1).

XRD analysis. The XRD data showed that the particles were crystalline in nature and patterns of the particles are 


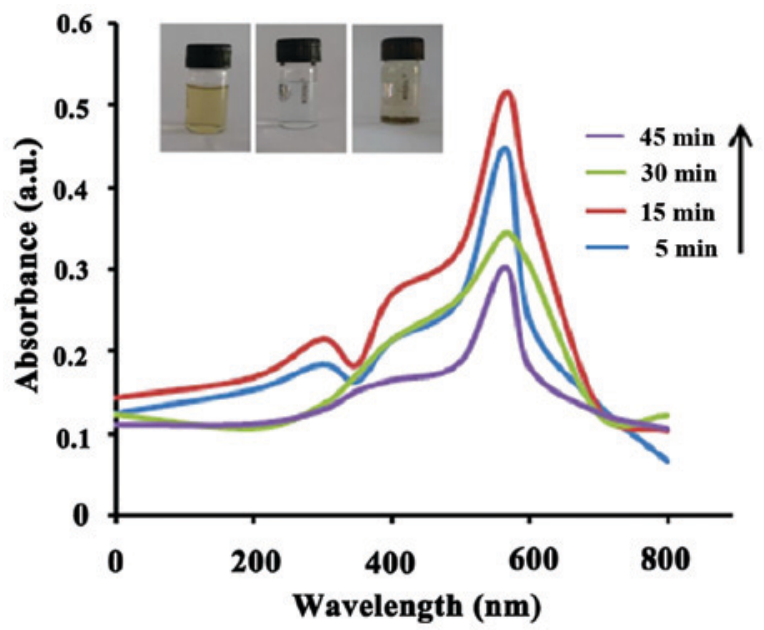

Figure 1. Ultraviolet-visible absorption spectrum of Eclipta prostrata plant leaf extract and biosynthesized copper nanoparticles at the indicated time intervals.

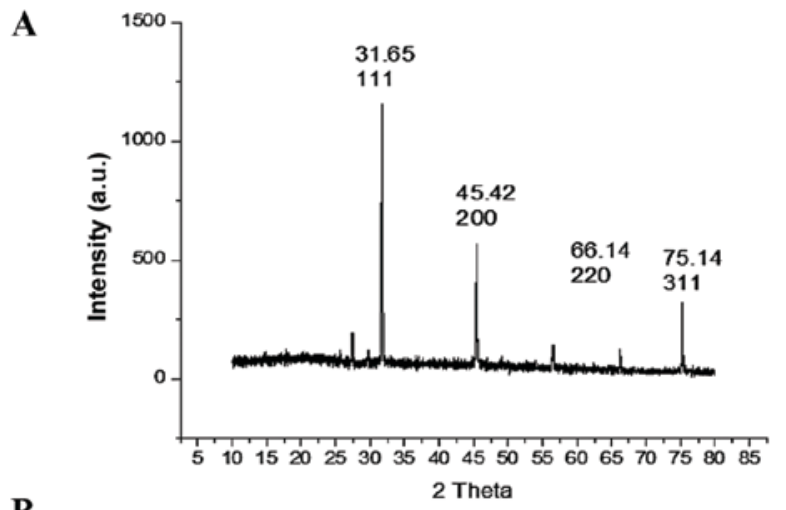

B

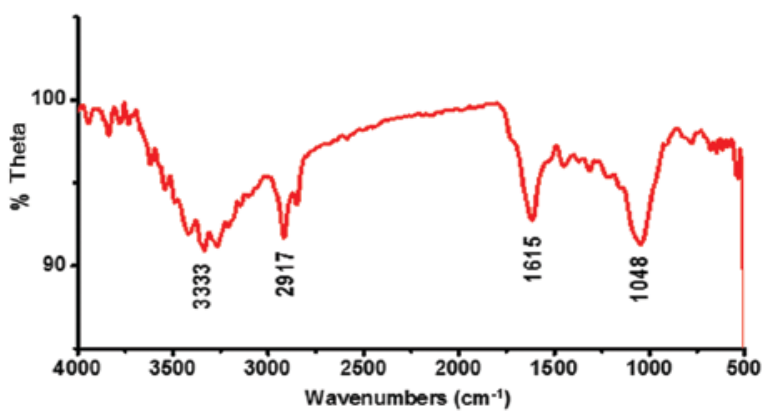

Figure 2. (A) X-ray diffraction pattern and (B) Fourier transform infrared spectroscopy spectra of copper nanoparticles synthesized by treating $\mathrm{AgNO}_{3}$ solution with Eclipta prostrata leaf extract.

specified in Fig. 2A. This suggests a monoclinic configuration and the diffraction data were in good coordination with the Joint Committee on Powder Diffraction Standards card (no. 89-5899). The diffraction patterns exhibited concentric rings corresponding to 31.65 (111), 45.42 (200), 66.14 (220) and 75.14 (311) reflections. These distances are characteristic of the face-centered cubic (FCC) structure of copper metal, ranging from 23 to $57 \mathrm{~nm}$ with an average size of $31 \pm 1.2 \mathrm{~nm}$.

FTIR analysis. In the present study, the FTIR spectrum was examined to identify the possible biomolecules responsible for capping and efficient stabilization of the CuNPs synthesized by E. prostrata leaf extract. Peaks were observed at $3,333 \mathrm{~cm}^{-1}$ for the hydroxy group (H-bonded $\mathrm{OH}$ stretch); $2,917 \mathrm{~cm}^{-1}$ for methylene C-H asym./sym. stretch; $1,615 \mathrm{~cm}^{-1}$ for aromatic ring stretch; and $1,048 \mathrm{~cm}^{-1}$ for aliphatic fluoro compounds (C-F stretch) (Fig. 2B).

SEM analysis. SEM micrographs of the CuNPs synthesized by the reduction of copper acetate revealed spherical, hexagonal and cubical NPs ranging from 28 to $105 \mathrm{~nm}$, with an average size of $41 \pm 0.8 \mathrm{~nm}$ due to $\mathrm{Cu}$ ions. It was observed that they were approximately spherical in shape with a smooth surface (Fig. 3A). The EDX of the synthesized CuNPs showed strong copper signals along with $\mathrm{P}$ and $\mathrm{C}$ peaks, which may originate from the biomolecules that were bound to the surface of the CuNPs (Fig. 3B).

HRTEM analysis. CuNPs were characterized by HRTEM to determine the morphology and size of the CuNPs, which revealed that the powder particles were agglomerated and the spherical-shaped NPs, (Fig. 3C). Aqueous extracts and $3 \mathrm{mM} \mathrm{Cu}(\mathrm{OAc}) 2$ solution exhibited monodisperse and spherical particles with sizes ranging from 28 to $45 \mathrm{~nm}$ and (mean, $36 \pm 1.2 \mathrm{~nm}$ ). The SAED pattern exhibited a set of rings containing spots suggesting that NPs have a larger grain size, uniform shape and are polycrystalline in nature (Fig. 3D).

Total antioxidant activity. In CuNPs synthesized using aqueous leaf extract of E. prostrata, the total antioxidant activity was found to be high in synthesized NPs and the aqueous leaf extract of E. prostrata at the different concentrations of $100,200,300,400$ and $500 \mu \mathrm{g} / \mathrm{ml}$, respectively. The aqueous leaf extract of $E$. prostrata demonstrated values of $0.26 \pm 0.06$, $0.39 \pm 0.14,0.43 \pm 0.11,0.59 \pm 0.67$ and $0.67 \pm 0.78 \mathrm{mg} \mathrm{GAE} / \mathrm{g}$; standard ascorbic acid values were: $0.51 \pm 0.11,0.56 \pm 0.06$, $0.64 \pm 0.15,0.71 \pm 0.25$ and $0.75 \pm 0.84 \mathrm{mg} \mathrm{GAE} / \mathrm{g}$; and CuNPs values were $0.54 \pm 0.19,0.47 \pm 0.67,0.72 \pm 920.79 \pm 0.56$ and $0.96 \pm 0.30 \mathrm{mg} \mathrm{GAE} / \mathrm{g}$, respectively (Fig. 4A).

The TPCs of CuNPs and aqueous leaf extract of E. prostrata were investigated by Folin-Ciocalteu assay. TPC values were expressed as mg of GAE/g of the CuNPs and aqueous extract. The synthesized CuNPs and the aqueous extract NPs showed the highest TPC of $14.3 \pm 1.47$ and $76.6 \pm 0.87 \mathrm{mg}$ of GAE/g, respectively.

Antioxidant activity of CuNPs and aqueous leaf extract of E. prostrata was assessed by DPPH free radical scavenging assay, using ascorbic acid as positive control, at various concentrations $(100,200,300,400$ and $500 \mu \mathrm{g} / \mathrm{ml}$, respectively). The mean percentage inhibition values of synthesized CuNPs and powdered leaves of E. prostrata were 32, 34, 41, 46 and 53\%; and $29,32,37,43$ and $48 \%$, respectively. The control values of ascorbic acid were $85,87,89,92$ and $95 \%$ with the increasing concentrations of NPs (Fig. 4B).

Cell viability assay. The effect of CuNPs and aqueous leaf extract of E. prostrata on the growth and morphology of the human HepG2 cancer cell line was studied using the MTT assay to evaluate the effect on cell viability. In vitro cytotoxicity of the CuNPs was evaluated against HepG2 cell lines at $1,10,100,250$ and $500 \mu \mathrm{g} / \mathrm{ml}$, which exhibited the cellular 

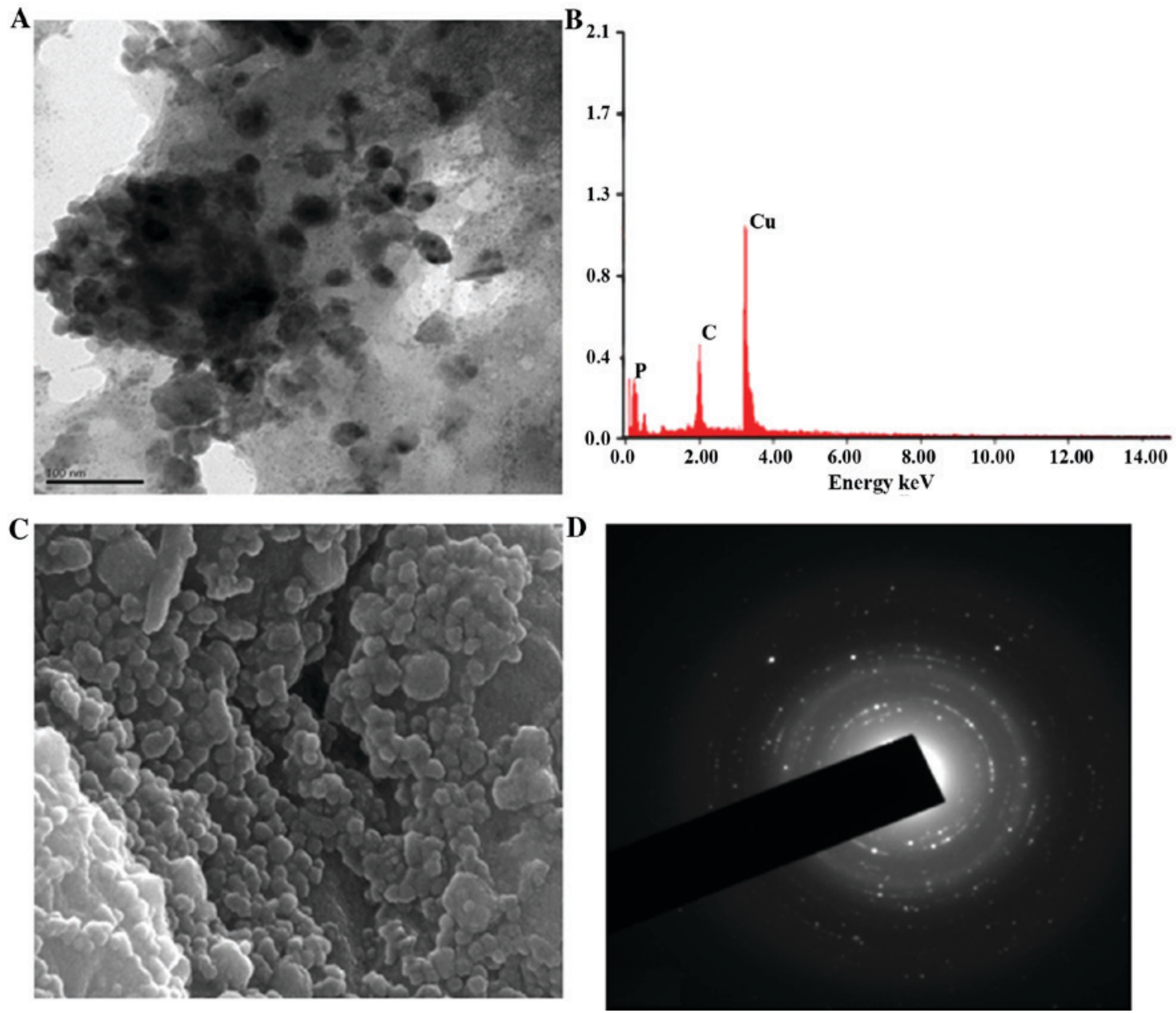

Figure 3. (A) Scanning electron microscope micrograph, (B) energy-dispersive X-ray spectrum (C) high-resolution transmission electron microscopy and (D) selected area diffraction patterns of copper nanoparticles synthesized by Eclipta prostrata leaf extract.

toxicity values of $3.0,15.5,28.5,44.5$ and $54.5 \%$, respectively (Fig. 5).

\section{Discussion}

In the present study, characteristic UV-spec absorption peak was observed at $565 \mathrm{~nm}$ and may be due to the surface plasmon band of $\mathrm{Cu}$ colloids formation of non-oxidized CuNPs. The broadness of the absorption band may arise from the wide size distribution of CuNPs. Terminalia arjuna bark extract was mixed with $\mathrm{Cu}\left(\mathrm{NO}_{3}\right)_{2}$ before and after microwave irradiation and the color of the solution gradually turned to dark brown, which indicated the reduction of CuNPs (20).

In the present study, the diffraction patterns exhibited concentric rings corresponding to 31.65 (111), 45.42 (200), 66.14 (220) and 75.14 (311) reflections. These distances are characteristic of the FCC structure of copper metal, ranging from 23 to $57 \mathrm{~nm}$ with a mean size of $31 \pm 1.2 \mathrm{~nm}$. This is consistent with findings published by Ramyadevi et al (21).

In the present study, the FTIR spectrum was examined to identify the possible biomolecules responsible for capping and efficient stabilization of the CuNPs synthesized by E. prostrata leaf extract were observed. Peaks were as follows: $3,333 \mathrm{~cm}^{-1}$ for the hydroxy group (H-bonded $\mathrm{OH}$ stretch); $2,917 \mathrm{~cm}^{-1}$ for methylene C-H asym./sym. stretch; $1,615 \mathrm{~cm}^{-1}$ for aromatic ring stretch; and $1,048 \mathrm{~cm}^{-1}$ for aliphatic fluoro compounds (C-F stretch). Similar results were observed in CuNPs synthesized by using the latex of $C$. procera, which showed strong absorption band at $1,610 \mathrm{~cm}^{-1}$ for $-\mathrm{NH} \mathrm{C}=\mathrm{O}$ to metals CuNPs (14).

In the present study, the SEM micrographs of the CuNPs synthesized by the reduction of copper acetate revealed spherical, hexagonal and cubical NPs ranging from 28 to $105 \mathrm{~nm}$ with an average size of $41 \pm 0.8 \mathrm{~nm}$ due to the $\mathrm{Cu}$ ions. Similar results were observed from the SEM micrographs of nanoparticles obtained in the filtrate, which showed that the CuNPs produced by Penicillium citrinum were spherical shaped with an average size of $24.5 \mathrm{~nm}$ (22). TEM images of the soya bean-synthesized CuNPs were spherical in shape with a smooth surface, morphology was more or less uniform in size and shape with a mean diameter of $\sim 40 \mathrm{~nm}$ for the nanoparticles (23).

Aqueous Piper longum fruit extract and green synthesized AgNPs have exhibited powerful antioxidant properties in in vitro antioxidant assays (24). The in vitro antioxidant properties of the biosynthesized AgNPs using Syzygium cumini seed extract have been evaluated and these nanoparticles were found to have a higher antioxidant capacity when compared to the seed extract (25). Thus, these can be used as potential radical scavengers against deleterious damages caused by free radicals. 

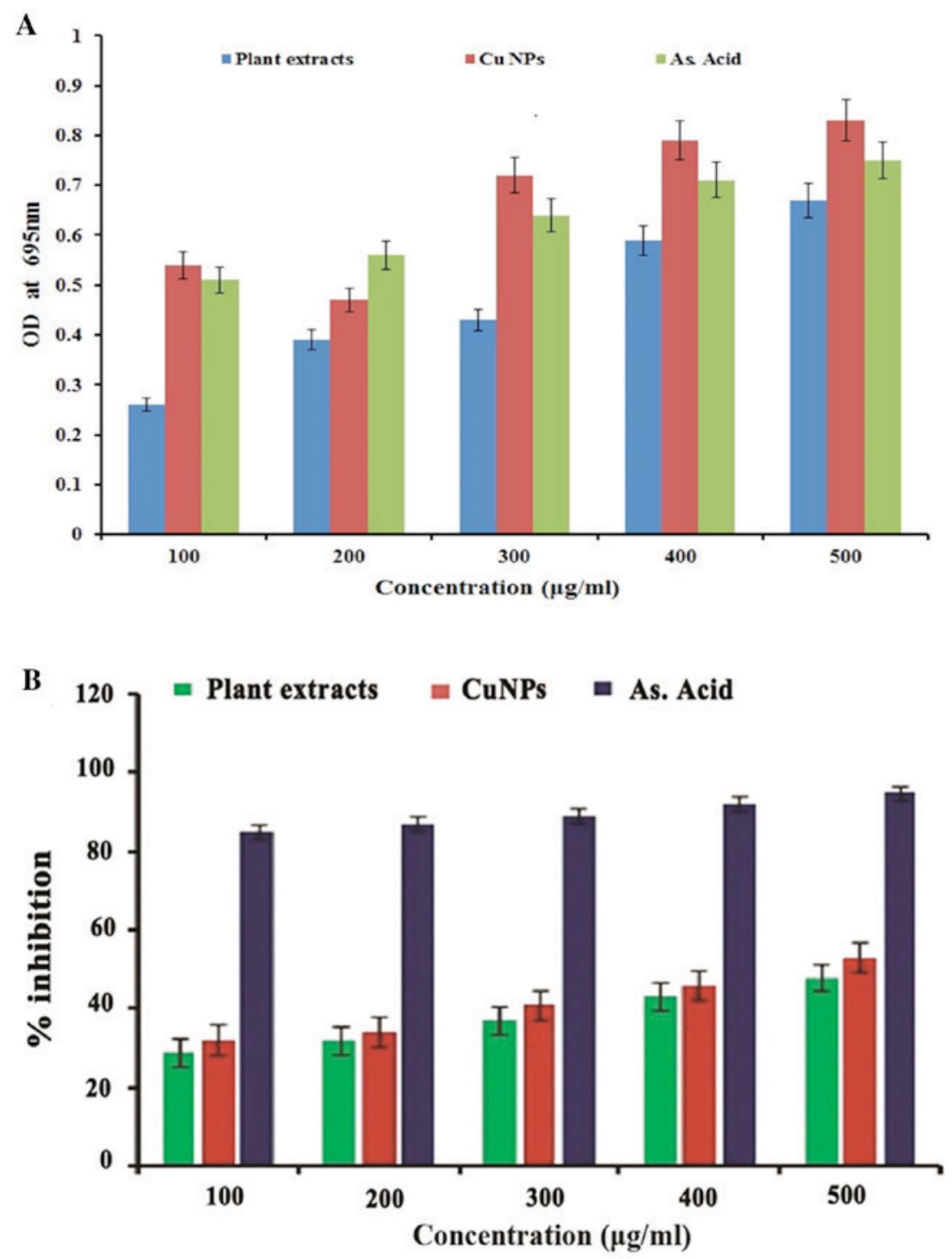

Figure 4. (A) Total antioxidant activity of synthesized CuNPs as compared with ascorbic acid as a standard antioxidant. (B) 1,1-diphenyl-2-picryl-hydrazyl free radical scavenging activity of different concentration of CuNPs. Data are presented as the mean \pm standard deviation. CuNPs, copper nanoparticles; OD, optical density.

A

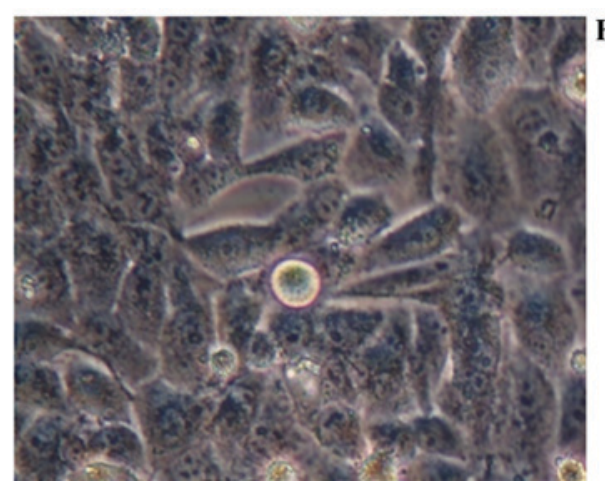

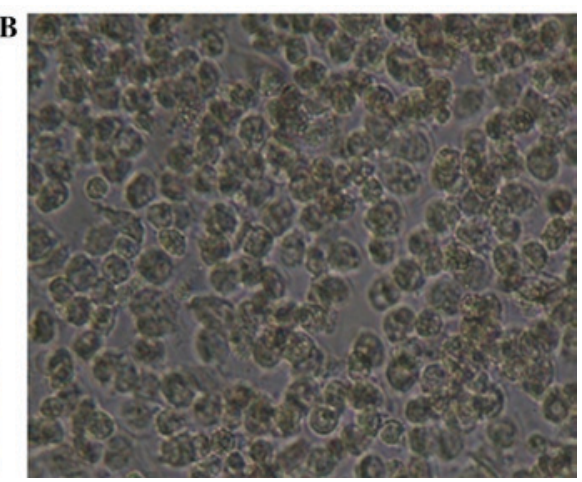

Figure 5. Cytotoxic effect of synthesized copper nanoparticles against HepG2 cancer cell line. Representative images demonstrate cell toxicity (\%) at different concentrations stained with purple blue formazan. Magnification, x1,000. (A) control and (B) $500 \mu \mathrm{g} / \mathrm{ml}$.

The total phenolic compounds and total flavonoides were higher in AgNPs-containing plant extract, as compared with the plant extract; and AgNPs-containing leaf extract showed a higher antioxidant activity when compared with Chenopodium murale leaf extract (26). The total phenolic compounds contained within the synthesized AgNPs using Iresine herbstii 
demonstrated the attachment of lower amounts (mg GA/g nanoparticles) of phenolic compounds. The phenolic content was compared with the leaf ethanolic extract of I. herbstii as mg of GAE (27).

$\mathrm{CuO}$ nanoparticles exhibited free radical scavenging activity that increased in $1 \mathrm{~h}$, which is relatively higher in comparison with other metal oxide nanoparticles (28). The DPPH activity of the nanoparticles was found to increase in a dose-dependent manner. However, the I. herbstii using AgNPs exhibited more inhibition with more scavenging activity of DPPH than I. herbstii leaf ethanolic extract (27).

Necrosis and cytopathic effects increased with increasing NP concentration, leading to cell damage (29). In a previous study, AgNPs formed using the aqueous leaf extract of mistletoe (Dendrophthoe falcate) showed a prominent cytotoxicity effect against human breast carcinoma cells (MCF-7) at a minimal dosage of $5 \mu \mathrm{l} / \mathrm{mg}$ (30). The cytotoxic activity of Acalypha indica-mediated CuNPs was evaluated by MTT assay against MCF-7 breast cancer cell lines, which confirmed that CuNPs exhibit cytotoxic activity (31). Synthesis of AgNPs from Melia dubia leaf extract showed remarkable cytotoxic activity against a KB cell line, with evidence of a high therapeutic index value (32). Cytotoxicity assessment of biosynthesized AgNPs using aqueous latex extract of Calotropis gigantea showed enhanced anticancer potential (33).

In conclusion, in the Indian Ayurvedic medicine system E. prostrata is an ethnomedically valuable plant species known to have potential applications in the treatment of various diseases. To explore its therapeutic value and nanobiotechnological potential, the present study synthesized CuNPs using latex extract of E. prostrata. Biosynthesized CuNPs were characterized by UV-Vis spectrometry, FTIR, XRD, EDX and HRTEM. In addition, to structural characterization, antioxidant and MTT assays were used assess the biosynthesized CuNPs. The present findings suggest that CuNPs may be developed into promising drug candidates with various biomedical applications.

\section{Acknowledgments}

This paper was supported by the KU-Research Professor Program of Konkuk University, Seoul, South Korea.

\section{References}

1. Shobha G, Vinutha M and Ananda S: Biological synthesis of copper nanoparticles and its impact - a review. Int J Pharmaceut Sci Invent 3: 28-38, 2014.

2. Han WK, Choi JW, Hwang GH, Hong SJ, Lee JS and Kang SG: Fabrication of $\mathrm{Cu}$ nano particles by direct electrochemical reduction from CuO nano particles. App Surf Sci 252: 2832-2838, 2006.

3. Ponce AA and Klabunde KJ: Chemical and catalytic activity of copper nanoparticles prepared via metal vapor synthesis. J Mol Catal 225: 1-6, 2005.

4. Huang Z, Cui F, Kang H, Chen J, Zhang X and Xia C: Highly dispersed silica-supported copper nanoparticles prepared by precipitation-gel method: A simple but efficient and stable catalyst for glycerol hydrogenolysis. Chem Mater 20: 5090-5099, 2008.

5. Dhas NA, Raj CP and Gedanken A: Synthesis, characterization, and properties of metallic copper nanoparticles. Chem Mater 10: 1446-1452, 1998.

6. Park BK, Jeong S, Kim D, Moon J, Lim S and Kim JS: Synthesis and size control of monodisperse copper nanoparticles by polyol method. J Colloid Interface Sci 311: 417-424, 2007.
7. Valodkar M, Jadeja RN, Thounaojam MC, Devkar RV and Thakore S: Biocompatible synthesis of peptide capped copper nanoparticles and their biological effect on tumor cells. Mater Chem Phys 128: 83-89, 2011.

8. Lee H, Song JY and Kim BS: Biological synthesis of copper nanoparticles using Magnolia kobus leaf extract and their antibacterial activity. J Chem Technol Biotechnol 88: 1971-1977, 2013.

9. Gopinath M, Subbaiya R, Masilamani Selvam M and Suresh D: Synthesis of copper nanoparticles from Nerium oleander leaf aqueous extract and its antibacterial activity. Int J Curr Microbiol App Sci 3: 814-818, 2014.

10. Zhong XK, Li DC and Jiang JG: Identification and quality control of Chinese medicine based on the fingerprint techniques. Curr Med Chem 16: 3064-3075, 2009.

11. Yahara S, Ding N, Nohara T, Masuda K and Ageta H: Taraxastane glycosides from. Eclipta alba. Phytochem 44: 131-135, 1997.

12. Santhosh KC, Govindasamy S and Sukumar E: Lipid lowering activity of Eclipta prostrata in experimental hyperlipidemia. J Ethnopharmacol 105: 332-335, 2006.

13. Prachayasittikul S, Wongsawatkul O, Suksrichavalit T, Ruchirawat S and Prachayasittikul V: Bioactivity evaluation of Eclipta prostrata linn: A potential vasorelaxant. Eur J Sci Res 44: 167-176, 2010.

14. Harne S, Sharma A, Dhaygude M, Joglekar S, Kodam K and Hudlikar M: Novel route for rapid biosynthesis of copper nanoparticles using aqueous extract of Calotropis procera $\mathrm{L}$. latex and their cytotoxicity on tumor cells. Colloids Surf B Biointerfaces 95: 284-288, 2012.

15. Prieto P, Pineda M and Aguilar M: Spectrophotometric quantitation of antioxidant capacity through the formation of a phosphomolybdenum complex: Specific application to the determination of vitamin E. Anal Biochem 269: 337-341, 1999.

16. Amin I, Norazaidah Y and Emmy Hainida KI: Antioxidant activity and phenolic content of spinach species. Food Chem 94: 47-52, 2006.

17. Liyana-Pathiranan CM and Shahidi F: Antioxidant activity of commercial soft and hard wheat (Triticum aestivum L.) as affected by gastric $\mathrm{pH}$ conditions. J Agric Food Chem 53: 2433-2440, 2005.

18. Mosmann T: Rapid colorimetric assay for cellular growth and survival: Application to proliferation and cytotoxicity assays. J Immunol Methods 65: 55-63, 1983.

19. Ahamed M, Akhtar MJ, Siddiqui MA, Ahmad J, Musarrat J, Al-Khedhairy AA, AlSalhi MS and Alrokayan SA: Oxidative stress mediated apoptosis induced by nickel ferrite nanoparticles in cultured A549 cells. Toxicology 283: 101-108, 2011.

20. Yallappa S, Manjanna J, Sindhe MA, Satyanarayan ND, Pramod SN and Nagaraja K: Microwave assisted rapid synthesis and biological evaluation of stable copper nanoparticles using T. arjuna bark extract. Spectrochim Acta A Mol Biomol Spectrose 110: 108-115, 2013.

21. Ramyadevi J, Jeyasubramanian K, Marikani A, Rajakumar G and Rahuman AA: Synthesis and antimicrobial activity of copper nanoparticles. Mat Lett 71: 114-116, 2012.

22. Honary S, Barabadi H, Gharaei-Fathabad E and Naghibi F: Green synthesis of copper oxide nanoparticles using Penicillium aurantiogriseum, Penicillium citrinum and Penicillium waksmanii. Dig J Nanomat Biostruct 7: 999-1005, 2012.

23. Guajardo-PachecoMaJ,Morales-SánchezJE,González-HernándezJ and Ruiz F: Synthesis of copper nanoparticles using soybeans as a chelant agent. Mat Lett 64: 1361-1364, 2010.

24. Reddy NJ, Nagoor Vali DN, Rani M and Rani SS: Evaluation of antioxidant, antibacterial and cytotoxic effects of green synthesized silver nanoparticles by Piper longum fruit. Mat Sci Eng C Mater Biol Appl 34: 115-122, 2014.

25. Banerjee $J$ and Narendhirakannan R: Biosynthesis of silver nanoparticles from Syzygium cumini (L.) seed extract and evaluation of their in vitro antioxidant activities. Digest J Nanomat Biostruct 6: 961-968, 2011.

26. Abdel-Aziz MS, Shaheen MS, EL-Nekeety AA, Mosaad A and Abdel-Wahhab MA: Antioxidant and antibacterial activity of silver nanoparticles biosynthesized using Chenopodium murale leaf extract. J Saudi Chem Soc 18: 356-363, 2014.

27. Dipankar C and Murugan S: The green synthesis, characterization and evaluation of the biological activities of silver nanoparticles synthesized from Iresine herbstii leaf aqueous extracts. Colloids Surf B Biointer 98: 112-119, 2012.

28. Das D, Nath BC, Phukon P and Dolui SK: Synthesis and evaluation of antioxidant and antibacterial behavior of $\mathrm{CuO}$ nanoparticles. Colloids Surf B Biointerfaces 101: 430-433, 2013. 
29. Rainey GJ and Coffin JM: Evolution of broad host range in retroviruses leads to cell death mediated by highly cytopathic variants. J Virol 80: 562-570, 2006.

30. Sathishkumar G, Gobinath C, Wilson A and Sivaramakrishnan S: Dendrophthoe falcate (L.f) Ettingsh (Neem mistletoe): A potent bioresource to fabricate silver nanoparticles for anticancer effect against human breast cancer cells (MCF-7). Spectrochim Acta A Mol Biomol Spectrosc 128: 285-290, 2014.

31. Sivaraj R, Rahman PK, Rajiv P, Narendhran S and Venckatesh R: Biosynthesis and characterization of Acalypha indica mediated copper oxide nanoparticles and evaluation of its antimicrobial and anticancer activity. Spectrochim Acta A Mol Biomol Spectrose 129: 255-258, 2014
32. Kathiravan V, Ravi S and Ashokkumar S: Synthesis of silver nanoparticles from Melia dubia leaf extract and their in vitro anticancer activity. Spectrochim Acta A Mol Biomol Spectrosc 130: 116-121, 2014.

33. Rajkuberan C, Sudha K, Sathishkumar G and Sivaramakrishnan S: Antibacterial and cytotoxic potential of silver nanoparticles synthesized using latex of Calotropis gigantea $\mathrm{L}$. Spectrochim Acta A Mol Biomol Spectrosc 136: 924-930, 2015. 